\title{
Massive pericardial effusion in a hypothyroid child
}

\author{
L H P WILliaMS, ^ R JAYATUNGA, $\dagger$ O SCOTT $\ddagger$ \\ From the Department of Paediatrics, ${ }^{\star}$ Kilton Hospital, Worksop; $†$ Nether Edge Hospital, Sheffield; and the \\ †Killingbeck Hospital, Leeds
}

SUMMARY A child with Down's syndrome and long standing severe hypothyroidism had a massive pericardial effusion without cardiac tamponade. The effusion completely resolved with medical treatment without pericardiocentesis.

Pericardial effusion may be found in as many as $30 \%$ of adult patients with hypothyroidism. ${ }^{1}$ It appears to be a very rare finding in paediatric practice since only one child with this condition has been reported. ${ }^{2}$ We report another case of a hypothyroid child with a pericardial effusion and outline the successful medical management.

\section{Case report}

A 14 year old child with Down's syndrome was referred to us with signs and symptoms of severe hypothyroidism. His bone age was only 6 years while the thyroid function tests gave the following results: serum thyroxine concentration, $20 \mathrm{nmol} / 1(15 \cdot 5 \mu \mathrm{g} / \mathrm{l})$ (normal 70-170 nmol/1; 54.3-132.1 $\mu \mathrm{g} / 1$ ); serum triiodothyronine concentration $0.2 \mathrm{nmol} / 1(13.0 \mathrm{ng} / \mathrm{dl})$ (normal 1-2.5 nmol/1; 65.1-162.7 ng/dl); serum triiodothyronine uptake $83 \%$ (normal $85-115 \%$ ); and thyroid stimulating hormone concentration $40 \mathrm{mU} / \mathrm{l}$ (normal 0-8 mU/l). The history suggested that the condition had been long standing. The child was lethargic but not ill, and no abnormal cardiovascular signs were noticed on the initial examination except that the heart sounds were quiet. A chest radiograph was not performed at that time.

He was treated with $25 \mu \mathrm{g}$ thyroxine sodium a day with definite clinical improvement and the dose was increased to $50 \mu \mathrm{g}$ a day after eight weeks. After this increment, he complained of shortness of breath and

Requests for reprints to Dr L H P Williams, Department of Paediatrics, Kilton Hospital, Worksop, Notts S81 0BD. tiredness, which disappeared on reducing the dose to $25 \mu \mathrm{g}$ a day. Two weeks later he suddenly became severely short of breath and had central chest pain. He had recovered by the time he was brought to hospital.

On examination the apex beat could not be palpated, the heart sounds were very quiet, but there was no pericardial rub. A chest $x$ ray film showed a large globular heart suggesting a pericardial effusion (Fig. 1) and the electrocardiogram showed low voltage in every lead with electrical alternans. The pericardiothoracic ratio was 0.71 . An echocardiogram confirmed the presence of a large pericardial effusion (Fig. 2). The patient appeared remarkably well despite such a massive effusion, and since there was no evidence of tamponade medical treatment was continued. The

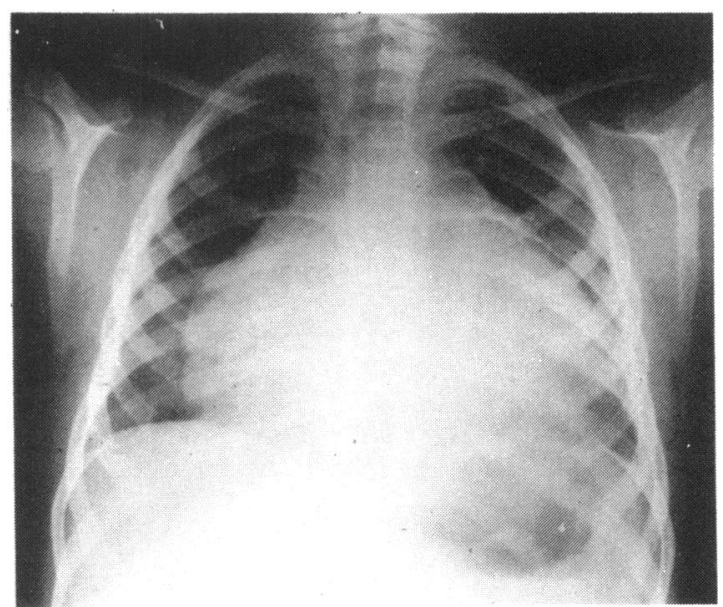

Fig. 1 Chest radiograph showing gross cardiomegaly. 


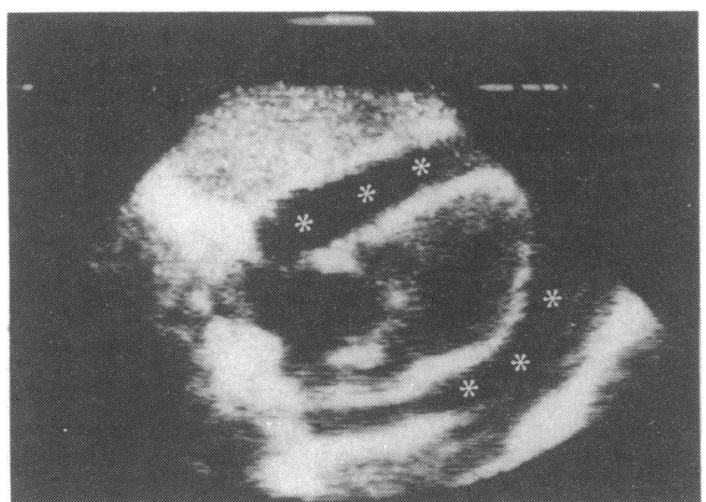

Fig. 2 Cross sectional echocardiogram of the heart lying in a large pericardial effusion (marked with asterisks).

dose of thyroxine was slowly increased and no further cardiovascular symptoms occurred. After seven months of treatment, the heart remained very large (cardiothoracic ratio 0.65 ). Two months later, the heart size had returned to normal (cardiothoracic ratio 0.42 ), and the electrocardiogram was normal. An echocardiogram showed that the effusion had completely resolved.

The biochemical tests still showed mild hypothyroidism, however, although he was clinically euthyroid. His serum thyroxine concentration was $63 \mathrm{nmol} / 1$ $(48.9 \mu \mathrm{g} / \mathrm{l})$ and his thyroid stimulating hormone concentration $9.5 \mathrm{mU} / 1$.

He remained asymptomatic and a month later, after an increase of the dose of thyroxine to $125 \mathrm{mg}$ a day, thyroid function tests showed no abnormalities.

\section{Discussion}

The only previous paediatric case report of juvenile hypothyroidism with pericardial effusion occurred in a 12 year old with Down's syndrome. ${ }^{2}$ Down's syndrome is known to be associated with thyroid disorders. In our patient the effusion was probably present at the initial examination of the child but was not detected on clinical examination. Dyspnoea developed as the dose of thyroxine was increased but disappeared when the dose was reduced. Two weeks later dramatic symptoms prompted the cardiac assessment which showed the effusion. There was no tamponade despite the enormous effusion, and this is presumably because the fluid accumulated so slowly. The effusion resolved slowly over 10 months with treating with thyroxine only.

Our management is in accord with the findings of Ivy and Smolar et al who found that resolution occurred during thyroxine replacement therapy. ${ }^{34}$ Rasmussen $e t$ al in a juvenile ${ }^{2}$ and Ivy and Smolar et al in adults ${ }^{34}$ found that after drainage the pericardial effusion recurred and regressed only after thyroxine treatment.

We conclude that other hypothyroid children with less obvious cardiomegaly might have pericardial effusions which would only be recognised by echocardiography. If an effusion is found thyroxin replacement should be started with a small dose and increased very gradually in order to avoid the need to reduce the dose at any stage. Thyroid replacement alone will result in the resolution of the effusion, although it may take many months. Pericardiocentesis is unnecessary unless cardiac tamponade occurs.

\section{References}

1 Hardisty CA, Naik DR, Munro DS. Pericardial effusion in hypothyroidism. Clin Endocrinol (Oxf) 1980; 13: 34954.

2 Rasmussen N, Vazquez AM, Tripp ME, Neal W. Pericardial effusion: a complication of hypothyroidism. Am $\mathcal{F} D$ is Child 1979; 133: 329.

3 Ivy HK. Myxedema precoma, complications and therapy. Mayo Clin Proc 1965; 40; 403-14.

4 Smolar EN, Rubin JE, Avramides A, Carter AC. Cardiac tamponade in primary myxedema and review of the literature. Am F Med Sci 1976; 272: 345-52. 